\title{
BRASIL: DOENÇAS EMERGENTES OU REEMERGENTES?
}

\author{
BRAZIL: EMERGING OR RE-EMERGING DISEASES?
}

Antonio Ruffino Netto

Docente do Departamento de Medicina Social da Faculdade de Medicina de Ribeirão Preto da Universidade de São Paulo.

Doenças emergentes têm sido definidas como aquelas cuja incidência nos seres humanos tem aumentado nas últimas décadas. AIDS, por exemplo, ilustra bem a definição. No período de 1980 a 1997 (especificamente até 01-03-97) foram notificados, no Brasil, 103.262 casos*.

Doenças reemergentes são as que reaparecem após um período de declínio significativo.

O Brasil se apresenta numa fase de transição demográfica e epidemiológica e nele podemos encontrar um mosaico de doenças típicas do $1^{\circ}$, do $2^{\circ}$ e do $3^{\circ}$ mundo (áreas com prevalência de doenças crônicas ou de doenças infecto-parasitárias), assim como fartura de patologias emergentes e/ou reemergentes.

Para ilustração, vejamos alguns exemplos**:

Cólera - no período de 1991 a 1995, foram notificados 1.339.812 casos nas Américas, com a ocorrência de 11.338 óbitos. Somente o Brasil foi responsável por 328.421 casos (25\% do total das Américas) onde se verificaram 1.792 óbitos (16\% do total observado no continente).

A incidência da cólera no Brasil, para cada 100.000 habitantes, nesse período, foi de 203. Ocupou o $8^{\circ}$ lugar em notificações (suplantado apenas pelo Peru com incidência de 2.738; Equador com 776; Guatemala, 707; Nicarágua, 596; El Salvador, 525; Bolívia, 507 e Honduras com 241).

Quanto a outra doença, a Dengue, no ano de 1995, encontramos taxas de incidência/100.000 da seguinte ordem: Guiana Francesa, 779; Honduras, 764; Montserrat, 704; El Salvador, 546; Costa Rica, 515; República Dominicana, 452; Barbados, 258; Belize, 243 e Brasil, 223.

Quanto à Dengue Hemorrágica, encontramos: Colômbia, 733; México, 355; El Salvador, 129; Brasil, 105 e Jamaica, 88.

Assim, em termos de incidência de Dengue, o Brasil ocupa o $8^{\circ}$ lugar e quanto a de Dengue Hemor- rágica ocupa o $4^{\circ}$, nas Américas.

Cólera e Dengue são duas doenças, sem dúvida alguma, reemergentes no país e no continente. Aparentemente controladas no passado, voltam a ocupar seu destaque no presente.

Já a Tuberculose, não chega propriamente a ser reemergente, pois nunca chegou a declinar significantemente, tampouco é doença emergente, pois, há tempo, apresenta incidência elevada. Sua ocorrência continua com alta magnitude. Em 1994, foram notificados 87.280 casos no Brasil; ocupou o $1^{\circ}$ lugar no Continente, sendo seguido pelo Peru com 48.601 casos; México com 16.353; Argentina com 13.683 e Equador com 9.685 casos. Levando-se em consideração a população exposta ao risco, e portanto, analisando-se os coeficientes por 100.000 habitantes, o Brasil passa a ocupar o $6^{\circ}$ lugar (com coeficiente de 54, sendo antecedido pelo Peru com 208; Bolívia, 130; Equador, 86; Honduras, 78 e Nicarágua, 64).

Em 1995, foram notificados, no Brasil, 90.664 casos novos e, em 1994, registrados 5.977 óbitos. Esse quadro da Tuberculose vem se agravando por várias razões: empobrecimento da população, sucateamento da Rede Pública de Assistência à Saúde e advento da AIDS com uma epidemia em expansão. A falta de priorização da Tuberculose pelos serviços responsáveis pelo seu controle vem abaixando a efetividade dos programas, e os índices de abandono do tratamento têm-se elevado em diferentes locais.

O Ministério da Saúde, através da Coordenação Nacional de Pneumologia Sanitária, está propondo um plano de ação emergencial para o controle da Tuberculose. Ainda bem. Caso contrário, estaremos ocupando lugares cada vez mais destacados, negativamente, em termos de notificação de doenças sejam emergentes e/ou reemergentes, ou mesmo daquelas que nunca saíram de foco, como é o caso da Tuberculose.

\footnotetext{
* Boletim Epidemiológico - AIDS - Ministério da Saúde - ANO IX (nº 5) página 14, 1997.

** WORLD HEALTH ORGANIZATION. Report of the Second WHO Meeting on Emerging Infectious Diseases. Document WHO/CDS/BVI/95.2 Geneva, 1995.
} 